\section{The role of libraries in misinformation programming: A research agenda}

\author{
Jason C. Young ${ }^{\mathrm{ID}}$, Brandyn Boyd, Katya Yefimova, \\ Stacey Wedlake ${ }^{D}$, Chris Coward and Rolf Hapel \\ University of Washington, USA
}

Journal of Librarianship and Information Science

C) The Author(s) 2020 Article reuse guidelines: sagepub.com/journals-permissions DOI: 10.1 1 77/0961000620966650 journals.sagepub.com/home/lis

\begin{abstract}
Misinformation, or fake news, has exploded across social media platforms and communities over the past few years, with serious social and political implications. Many library practitioners and organizations have argued that libraries can and should play a central role in educating the public about this emerging issue. However, serious gaps exist in understanding how libraries can create effective community education about misinformation. This article maps out a research agenda that researchers and public library practitioners can use to make libraries more effective sites for combatting misinformation. This research agenda is grounded in analysis of interviews and workshop discussions of public library staff from Washington State. This analysis reveals three areas in which academic partners can support public libraries: through the design of effective programming, through the development of tools that help librarians keep up-to-date on relevant misinformation, and through interventions in the political and economic contexts that hamper the freedom of librarians to engage controversial topics. Our hope is that this article can help to spur more expansive library and information science research across these areas and become the beginning of a longer and more empirically grounded conversation about how public libraries can achieve their potential for combating misinformation.
\end{abstract}

\title{
Keywords
}

Disinformation, media literacy, misinformation, public libraries, politics, programming

Misinformation, or fake news, has exploded across social media platforms and communities over the past few years, with serious social and political implications (Scheufele and Krause, 2019). Unfortunately, citizens do not yet have sufficient skills and tools to effectively navigate the flood of misinformation that they encounter in their everyday lives. Recent studies indicate that $64 \%$ of adults believe that misinformation leads to societal confusion and $23 \%$ of adults have (intentionally or unintentionally) spread misinformation themselves (Hodgin and Kahne, 2018). In a broad survey of current research, Fernandez and Alani (2018) find that misinformation has driven misperceptions across a wide range of areas, including the economy, health, climate change, foreign policy, and more. At the time of this writing, for example, the global spread of misinformation related to coronavirus (COVID-19) has been so great that researchers are referring to it as an "infodemic" (e.g. Pulido et al., 2020; World Health Organization (WHO) 2020; Zaracostas, 2020). In this context, misinformation can directly contribute to behavior that compromises public health and endangers individual lives. Evidence of the seriousness of these impacts include the World Economic
Forum's recent decision to list misinformation as one of the top 10 significant issues facing the world, and the decision by the Bulletin of Atomic Scientists to push the Doomsday Clock closer to midnight in response to the emergence of disinformation campaigns (Cook et al., 2018; Marks, 2020).

Researchers across a broad range of fields are scrambling to figure out the best approach to dealing with this new phenomenon (Koulolias et al., 2018). Some of the most explored approaches to combatting misinformation include policy change, technological solutions to factchecking, and education (e.g. Allcott et al., 2019; Asr and Taboada, 2018; Braten et al., 2019; Crocco et al., 2017; Farrell et al. 2019; Henderson et al., 2017; Kim et al., 2018; Simpson et al. 2019; Van der Linden et al., 2017). While a great deal of education research has focused on secondary and post-secondary education, public libraries have also been singled out as promising sites for providing

\section{Corresponding author:}

Jason C. Young, Information School, University of Washington, Bloedel Hall 060, Seattle, WA 98195, USA.

Email: youngjc2@uw.edu 
informal education to combat misinformation (e.g. ALA, $2005,2018)$. Despite this potential, however, to date, there has been little empirical proof that speaks to the real success of public libraries in combatting misinformation within their communities (Sullivan, 2019b). More research is therefore needed to understand the types of interventions that libraries can implement to transform their promise into broader successes. This article attempts to outline a research agenda that will help to encourage this success. It does so through the analysis of interviews of and discussions with public library staff across Washington State, which asked them to discuss their experiences with misinformation and their thoughts on how to design effective public services and programs related to misinformation. Library programming refers to a session or series of sessions, a workshop, or another experience on a particular topic, presented for entertainment, recreation, or to convey information. These discussions reaffirmed the great potential of public libraries to combat misinformation, and also highlighted barriers to success that further research might help to overcome. Based on these findings, the article suggests ways to move forward with library-based research on misinformation-related programming.

\section{Misinformation, education, and libraries}

As misinformation, or factually inaccurate information that is often spread via social media, has increasingly emerged into public awareness, many library practitioners and organizations have argued that libraries can and should play a central role in educating the public about the issue. (e.g. Banks, 2016; Becker, 2016; Dempsey, 2017; Jacobson, 2017; Kenney, 2017; Lewandowsky et al., 2017). They argue that librarians have actually been addressing misinformation for decades by helping the public stay informed, providing them with information and media literacy skills, and curating information sources (Banks, 2016). Practitioners argue that even though information and media literacy frameworks have not historically addressed misinformation directly, librarians can and should update existing approaches to counter new forms of misinformation (Banks, 2016; Becker, 2016; Cooke, 2017, 2018a, 2018b; LaPierre and Kitzie, 2019). Here, we talk about information literacy - the abilities needed to find, evaluate, and effectively use information-and media literacy - the abilities needed to access, evaluate, and act using all forms of communication - together because both are relevant to misinformation (ALA, 2019; National Association for Media Literacy Education, no date). Librarians tend to be generalists ready to engage interdisciplinary topics, and they regularly introduce patrons to new technology skills. Public libraries have also retained high levels of trust among the public, which is important given both general declines in trust of public institutions and the politically polarized nature of misinformation (Sullivan, 2019b). Based on these attributes, professional organizations like the American Library Association (ALA) have released resolutions opposing the spread of misinformation and affirming the role of libraries in educating the public on its harms (e.g. ALA, 2005, 2018). While many of the arguments in the literature have been more aspirational than empirical in nature, examples of library interventions have slowly begun to emerge. These emerging examples often draw on traditional information or media literacy frameworks, or simply point users to checklists or LibGuides, to help them find trusted information sources and assess the credibility of a particular resource (e.g. Ireland, 2017; Jacobson, 2017; NeelySardon and Tignor, 2018). Other approaches aim to educate patrons more broadly on journalism and social media (e.g. Koester, 2019; Wade and Hornick, 2018). The excitement and range of ideas presented by librarians in this area is a reason for optimism.

However, serious gaps still exist in understanding how libraries might transform this potential into effective community education about misinformation. Some librarians and researchers have pointed out the limitations to existing information frameworks for teaching misinformation and started to explore new models (Bluemle, 2018; Caulfield, 2016). Sullivan $(2018,2019$ a, 2019b) offers some of the most poignant criticism of the current state of library-based interventions in misinformation. He argues that there has been very little evaluation of the impact of existing library information programming (Sullivan, 2019b). Many of the claims emerging from the library and information science (LIS) fields are testable - for example, that the trustworthiness of libraries makes them more effective, or that librarybased media literacy programs have a positive impact on source evaluation - but have not been subjected to rigorous research or even internal evaluation. This is particularly important because libraries, Sullivan (2018) argues, are often adopting traditional programming approaches that may not be particularly effective against misinformation. Sullivan (2018) argues that libraries have gone too far in framing the issue as one of information literacy, which has led them to focus too exclusively on teaching these literacy skills. He argues that libraries have had difficulty in adapting to rapidly evolving online environments; that libraries too often adopt misinformation guides from other organizations, thereby undermining their own expertise; and that libraries ignore the unique psychological dimensions of misinformation (Sullivan, 2018).

The last criticism is particularly noteworthy because research within education and psychology underscores the problems with traditional information literacy and factchecking approaches. According to this literature, misinformation spreads effectively because it exploits personal beliefs to trigger emotional and psychological responses that encourage individuals to resist competing claims. As a 
result, individuals often do not want to use information literacy skills to debunk misinformation, even if they do have those skills. If educational approaches do not account for the interaction between personal beliefs (and emotion) and misinformation, then they will be far less effective at changing the behavior of students (or the general public). In fact, if programming introduces individuals to ideas that contradict their own beliefs, there is evidence that this programming can trigger forms of "hot cognition" (Hodgin and Kahne, 2018). Hot cognition, or the viewing of information through negative emotions, produces a range of backfire effects, or psychological effects that lead misinformation to actually become more entrenched in the individual. These effects include confirmation bias (individuals actively seek out ways to disprove new ideas), disconfirmation bias (individuals dismiss ideas that contradict their beliefs), prior attitude effect (individuals view sources that affirm their beliefs as more trustworthy and accurate), and more (Choy and Chong, 2018; Hodgin and Kahne, 2018). These issues are generally described as directional biases, and they can be further amplified by other social and political biases (e.g. Ecker and Ang, 2018; Li and Sakamoto, 2014; Merkeley, 2020). These effects are all reasons why traditional approaches to fact-checking and information literacy can actually produce the opposite of their intended effect.

Sullivan's criticism posits that libraries do not know enough about misinformation and are therefore not being creative enough in their approaches to combat it. He argues that this lack of creativity is preventing them from exploring how some of their other attributes might make them much more effective at addressing misinformation. For example, Sullivan (2019b) believes that libraries have not sufficiently explored how their trusted position within communities can be better leveraged in relation to misinformation. He hopes that his criticism will not deter libraries from engaging with misinformation, but instead will spur more rigorous research into how libraries can be most effective. As Sullivan (2019b) argues,

It is hoped that future discussions of how libraries might combat misinformation, in general or in relation to trust, will be more concrete, more aligned with contemporary misinformation research, and more willing to demonstrate the effectiveness of library interventions within that research program. p. 8)

It was within this context that the current study was carried out to understand the barriers that might be preventing public libraries from thinking more creatively about misinformation programming. Through this work, we have found that public librarians tend to have a much more nuanced understanding of misinformation than Sullivan describes, but that they nevertheless face significant barriers to transforming those understandings into effective programming. Findings from this study provide an important research agenda that LIS researchers and library practitioners can use to make libraries more effective sites for combating misinformation.

\section{Methods}

This article is part of a larger project working with public librarians to design and implement effective programming to address misinformation in their communities. Data for this article come from preliminary interviews and a workshop that had the primary goal of understanding public librarian perceptions of and experiences with misinformation; their perceptions of what types of public library programming might most effectively address misinformation; and the barriers that they face in implementing this programming. Here, we describe the methods used to collect each of these sets of data. These methods were reviewed and approved by the University of Washington Human Subjects Division, to ensure compliance with ethical and legal standards covering research with human participants.

The first stage of the research was to carry out semistructured interviews with library staff across Washington State. These interviews were carried out with 12 participants that represented nine public library systems across the state. The focus was on public libraries in rural and suburban areas, as well as areas undergoing demographic transitions. Libraries primarily serving Washington's major cities were not represented in our interview sample. The positions of participants ranged from library system administration, such as directors of library outreach and programming supervisors, to frontline librarians. During the interview, participants were asked several sets of questions. A first set of questions asked them about their role in the library, past education programs offered by their library, and how they advertise and evaluate these programs. These questions were designed to obtain a baseline understanding of effective programming offered by the libraries. A second set of questions then asked the participants about their prior experiences with misinformation, including whether they have had personal or professional experiences with misinformation, whether their library has ever done programs on misinformation, whether their patrons would be interested in such programming, and what they think would be an engaging and effective approach to teach their patrons about misinformation. A final group of questions then asked the participants whether they believed they had the capacity and interest to participate in future research about misinformation. This included discussions of barriers that might prevent them from implementing misinformation programming, and resources that could help them to overcome these barriers. Interviews were carried out through Zoom, a telecommunications platform, and were audio recorded for later analysis.

A second stage of the project invited staff from libraries and library support organizations from Washington State 
to attend a workshop on misinformation. There were 22 participants from seven different library systems and two organizations that support libraries. Some, but not all, of the workshop participants also participated in the prior interviews. Two of the participants participated in the workshop virtually because they were from distant, rural library systems, while the rest participated in person. The purpose of the workshop was both to provide librarians with additional information about the topic of misinformation and to elicit information from them that would be useful in designing library programming to combat misinformation. To accomplish these goals, the day-long workshop was divided into several sessions. The first session provided participants with an introduction to misinformation. The research team presented an introductory lecture on misinformation and disinformation, including the role that libraries might play in combating them. This lecture was designed to provide librarians with current knowledge on these topics to ensure that all participants had a common understanding of them. The second session then provided the participants with a summary of preliminary findings from the interviews described above. This session also included small group work, in which the participants discussed their reactions to these findings. They discussed their impressions of the findings, whether they felt that anything was missing from the summaries, and whether they have similar views as expressed in the interviews. The third session then engaged participants in more small group work, in which they discussed topics or themes that they believed would provide an ideal focus for programming related to misinformation. Participants discussed questions including: Should these topics be politically controversial, or will this deter participation? What specific topics are of most interest to communities? How would the librarians engage the topics? This led into the final session, in which small groups chose one topic that had been brainstormed in the previous session, and then discussed how they would design effective programming around that topic in a way that touches on misinformation. They discussed specific aspects of programming including formats, audiences, requirements, and more. Discussions during the small group work were audio recorded, and a researcher participated in each group as a moderator. The researcher also took unguided notes about the discussion.

Audio from both the interviews and workshop were later analyzed together. Taken together, these two sources included data from 10 Washington State library districts with a service area population of approximately 3.6 million people, or nearly, half the population of the state (Pelczar et al., 2020). Represented library districts covered urban, suburban, and rural populations in the eastern and western sides of the state. The researchers used the Dedoose software platform to perform an inductive analysis of all of the data using a grounded theory-based approach (Clarke, 2003; Glaser, 1978; Kitchin and Tate, 2000). The team looked for common trends that shed light on current library thinking about misinformation, barriers to the implementation of successful programming, and perceptions of what would make for an effective program to combat misinformation. Researchers used an iterative approach and triangulated codes across the different data sources to ensure consistency (Baxter and Eyles, 1997). Results of this analysis are discussed in the remainder of the article.

For both the interviews and workshop, we invited participants to either remain confidential or have their names shared in research findings. We would like to acknowledge the participation of the following individuals, who all gave explicit permission for their names to be shared: Joaquin Alvarado, Audrey Barbakoff, Amanda Brack, Mary Dempsey, Laurie Finlayson, John Fossett, Elenya Herring, Carla Hopkins, Rehka Kuver, Amita Lonial, Tess Mayer, Kathleen O'Keeffe, Melissa Pillo, Christine Schonhart, Amanda Six, Phil Spirito, Sharon Streams, Amy Tooley, and Jenna Zarzcki. We would also acknowledge the importance of all of our confidential participants. To minimize any risk associated with discussions about politically charged topics, we do not attribute names to specific quotes throughout this article. Participants are instead simply identified as either interview participants or workshop participants.

\section{Discussion of findings}

The librarians who participated in this research are highly interested in providing programming related to misinformation, and they do have the potential to be powerful actors. In the context of this study, Sullivan (2018, 2019a) is correct that libraries have not yet implemented much programming on misinformation, and they have done very little in the way of evaluation for those few programs that they have implemented. However, they have designed and implemented programming that covers many related issues, including civil discourse and engagement, controversial political issues, critical thinking skills, and media literacy. They have also had extensive conversations about misinformation with both colleagues and patrons, and generally recognize that misinformation is a deeply complex issue that traditional programming does not sufficiently address. For example, our participants discussed how misinformation intersected with other social processes and forms of inequality, including lack of access to information and technology, which cannot easily be addressed by media literacy. In the words of one participant,

We know many people don't have Internet access at home, they have limited access to news resources. And so I think there's a combination of just not being informed plus misinformation. And just, yeah, lacking the tools to navigate all the information that is available. You know, a lot of our communities come into our libraries and that's the place where they access the Internet. So it's kind of a . . . you know . . . it's. . . we're primed and ready to be . . . to provide some tools 
and resources to help with navigating those things but, you know, we're not sure about the best way to proceed. (Interviewee 1)

In other words, librarians recognize that the issue is complex and that they are positioned to respond, but they often do not feel they currently have the ability to effectively intervene. This participant went on to recognize that the political nature of misinformation made programming "complicated and kind of tricky," and they emphasized the need to frame interventions in ways that are "respectful and effective." (Interviewee 1) Other participants indicated that patrons often are "not interested necessarily in hearing anything that challenges that viewpoint, they really want something that supports it." (Interviewee 2) This represents implicit recognition of how the psychological dimensions of misinformation complicate any possible library interventions in the phenomenon.

Our discussions with these librarians revealed that the barriers they face to implementing effective programming are far more complex than those that Sullivan describes. It is not simply a matter of librarians feeling that they need to double down on traditional information and media literacy programs. Instead, they identified complex issues that limit their ability to confidently design and implement effective programming. Analysis revealed three broad areas in which more research is needed, to provide librarians with insights into how to overcome barriers and design effective programming. These include research into the most effective formats for misinformation programming; research into tools and training that can make librarians feel more confident in addressing misinformation as it emerges within their communities; and research into how to overcome political and economic barriers to misinformation programming. Each of these areas is discussed below.

\section{Effective programming formats}

The interviews and library workshop extensively explored programming formats, both in terms of what formats the librarians have used to engage their communities around various topics and what formats they believed would be most effective for addressing misinformation. The term format describes different types and structures of public events in library settings. Participants discussed various programming approaches aimed at engaging the public around various topics relevant to the local community. Frequently mentioned formats included panel discussions, presentations by experts, and facilitated conversations with community members.

While many librarians did believe that media and information literacy should play a part within an overall misinformation program, they also generally recognized that focusing just on these forms of literacy was insufficient. Contrary to what Sullivan described, our participants described a strong desire to engage misinformation across a broad variety of formats. However, they remained unclear on the most effective approaches, pointing toward the need for more research.

Participants identified a range of reasons why media or information literacy programs designed explicitly around misinformation likely would not be effective. Perhaps, the greatest concern was that programs focused exclusively on building skills to recognize misinformation would fail to capture the publics who would most benefit from the program. One participant said that programming focused on media literacy skills was unlikely to attract much of an audience because of perceived lack of relevance:

I don't think that getting people, that just sort of saying, we're going to teach you about media literacy. First of all, it's . . . it's unrealistic, just in terms of, what people are going to turn out for. [. . . ] especially in communities where people don't have a lot of resources in terms of financial or time, we have to be really careful about the time with them that we have. [. . .] I think the reframing has to relate to how to make things relevant for people in the here and now ... (Interviewee 3)

Other participants felt that media literacy-focused approaches to misinformation programming tend to appeal to community members who already have the skills to recognize misinformation. As one librarian noted, "You know, this program was called fake news. It's not going to appeal to . . . it's kind of preaching to the choir, a little bit in the title and the content" (Interviewee 1). This perspective, first surfaced in the interviews, was confirmed by workshop participants, who stressed the importance of programming being immediately and obviously relevant to peoples' daily lives. This perspective helps explain why only the "choir" of people already interested in misinformation and aware of its dangers will make time for a class about how to recognize misinformation. One workshop participant further argued that "fake news programming is not successful because people do not want to be the ones that are fooled" (Workshop Participant). Patrons will avoid misinformation programming because they would feel embarrassed if that programming reveals that they have been tricked into believing false things. In a colloquial sense, this description also conforms with psychological studies of backfire effects, since it describes how far individuals will go to avoid having their beliefs questioned. Others worried that media and information literacy courses, even if they did attract participants, would not solve the underlying political divisions that misinformation exacerbates. Workshop participants, therefore, believed that novel approaches would be necessary that could both attract participants and encourage them to change their behavior related to misinformation.

In fact, participants described a wide range of formats that they believed would be particularly effective in encouraging discussions around misinformation. Several 
interviewees, for example, believed that the most successful approach would be to simply encourage community discussions related to issues affected by misinformation. They believed that this format would allow individuals to come together and compare their points of view, share opinions, and build empathy. As one interviewee argued,

I think some of the most powerful program formats are people learning from each other. So, are there examples of ways that people could share, either intergenerationally, their experiences? Are there ways that people in a workshop format could build or design something, and then show it to someone else as an illustration of misinformation, and helping people feel more confident, and recognizing and responding to that, or identifying, you know, sources? (Interviewee 4)

There was a feeling that these formats could help people address the underlying community divisions that misinformation is meant to exploit in the first place. Some interviewees believed that an effective approach would be to organize panel discussions with experts, which combined expert presentations with input from community members. Other ideas drew on librarians' traditional strengths as community educators, adopting approaches, such as book discussions to the topic of misinformation. Still, other ideas emphasized novel techniques, such as hands-on exploration of misinformation through virtual reality.

Both the interviews and subsequent workshop discussions surfaced a range of opportunities to address misinformation indirectly in creative ways. Many participants said that addressing misinformation could be part of many, if not all of the programs offered at the library. For some interviewees, this approach makes the most sense because it allows them to leverage programs that already have popular followings. As one participant put it, "We may have the most success weaving this into other conversations or programming that we're offering rather than branding an entire series around misinformation" (Interviewee 4). This participant went on to argue that it should be included in all programs because every topic is impacted by misinformation in some way. They said that

really misinformation has the ability to be everywhere. And so I would think that it rather than being a topic on its own, it almost just becomes the responsibility of the library around information literacy, to weave it into all of the programming that we do. (Interviewee 4)

Another participant echoed the belief that addressing misinformation could be part of any program:

You know, I really think that misinformation is something that is so important in our world to address that it could be any, from a story time on up to an adult program. It could be incorporated in any one of those aspects. (Interviewee 5)

This represents a desire to think well beyond simply implementing media literacy courses.
Nevertheless, participants were unsure of the most optimal ways to frame misinformation programming to the public. One participant, for example, was concerned about how the wording used to describe a program would impact the audience:

So, what are the synonyms for misinformation or fake news or disinformation that library staff can become aware of and weave into the conversations that we're already having? So what does it look like just conversationally? What does it look like in a storytime where a library staff is connecting with parents or caregivers of young children? (Interviewee 4)

This quote highlights a persistent theme across our findings - one of the challenges of addressing misinformation in a library setting lies in the fact that misinformation is both immediately associated with a particular political discourse ("fake news") and other forms of exploitative online activity (e.g. online scams targeting seniors).

Participants debated how explicitly to highlight the fact that programming was addressing misinformation. There was wide recognition that the political connotation of misinformation warranted careful consideration in program planning. Several participants believed that it was best to approach the topic head-on while maintaining space for all participants to express their views. As one interviewee said,

I want to hit it head-on. I think people are civil enough that they at least, you know . . . here in town and out in my small towns, too, I think they're all civil enough to be able to listen to a different viewpoint and try to understand it. [. . .] I really think that civility will rule. (Interviewee 6)

Still others felt that the topic needs to be approached more tangentially and implicitly - an approach that one workshop participant dubbed "hiding the broccoli in the brownies." They believed that this approach was less likely to bring patrons to the library filled with "pre-emptive outrage" or feelings that the library was coming from a place of political bias. As an interviewee expressed,

I think that, in many ways, you kind of have to hide the vegetables. And like, even though it's very tempting to say, Okay, we're going to talk about misinformation, not everybody gets super excited by that, unfortunately, I wish that they did. I wish that people took this more seriously. But not everybody does. And the other thing, too, is you might you might invite biases into the room, simply by calling it misinformation. Well, I was told that well that's different than what I think because of that backfire effect, right. So I think that for me personally, I've integrated it into my programs, but I have not hosted a program called misinformation. (Interviewee 7)

Ultimately, there was no consensus about what the best approach might be, but there was a desire to learn from experts on how to navigate these complex issues. These 
discussions demonstrated that librarians hold views that are more consistent with scholarly writing on misinformation than Sullivan (2019) alleges. Although these participants were not using psychological language like "directional bias" or "prior attitude effect," they nevertheless were expressing views that are widely confirmed by scholars within misinformation studies. They also recognized the pitfalls of focusing exclusively on media and information literacy programs, and they were ready to experiment. Throughout, though, they also recognized that they do not have the resources or expertise to determine the best approach all on their own. They know that they would benefit from scholarly research on misinformation, but often do not know where to start to learn from this material. Librarians want to address misinformation, but they cannot do it alone-they need partnerships with researchers that can provide expertise and rigorous approaches to implementation and evaluation. This therefore represents an important area for further exploration for LIS researchers.

\section{Equipping librarians}

Beyond the issue of program formats, applied research is also needed to develop tools and training that can help librarians feel more confident in addressing misinformation across all of their programming. Given that generic media and information literacy programming is not sufficient for addressing misinformation, librarians need to feel comfortable discussing varied forms of misinformation as they relate to many different programming topics. This is, however, difficult because these topics emerge rapidly based on perceptions of community needs. Both the interviewees and workshop participants constantly emphasized that their programming must be highly responsive, timely, and grounded in the daily lives of their community members to attract patrons. This means that they are often dealing with brand new topics and are covering a lot of different ground. As one participant pointed out, they are constantly trying "to cast a wide net and knowing that the interests of our communities are broad." (Interviewee 2) They often convene multiple focus groups and network extensively to keep up with emerging issues. As another interviewee said,

Our librarians, they are involved in a lot of different network meetings and they also have community conversations. But the best ideas I think come from the moment when you're just, maybe you're out for lunch and you're just chatting with somebody [. . .] Or maybe they come to the front desk and they're looking for this specific topic. (Interviewee 7)

While this results in programming that meets the needs of patrons, it also means that librarians need to constantly respond to needs that are not necessarily grounded in their own expertise. During the course of this small project, for example, misinformation related to COVID-19 and the protests of systemic racism and police brutality erupted across social media. The dynamic and fast-moving nature of misinformation often places those that are trying to combat it in a defensive or reactive position, making it difficult to ever get ahead of the curve.

To make matters worse, librarians have also found that misinformation itself is interconnected with many other technology-related issues in the minds of their patrons. This means that they cannot just rely on generic misinformation resources, because their patrons also want to extend conversations about misinformation to topics including privacy, fraud, and more. This forces the librarians to juggle a lot of different domains. In discussing possible topics for misinformation programs, our participants identified things including Internet safety, identity security, phishing, and scams that attempt to exploit the elderly. This can quickly become overwhelming. Many of our participants ended up conflating many of these different phenomena, which can also lead to a muddled understanding and response to them.

Our participants felt that they are not sufficiently trained to engage misinformation across this constantly shifting terrain. Many felt that they are not even trained well enough to talk about misinformation generally, much less in the context of all of their programs. As mentioned before, most of our participants have not implemented programs directly about misinformation in the past. Some participants indicated that they had not done this because of a lack of confidence. One librarian, for example, said,

I think the reason I find it hard to address is because I don't think anyone on our staff is really strong in that expertise. I would love to address it head on. But I don't . . . I don't know who to have address that per se, who would be good, you know. Because all of the partners that we work with, nobody seems to ... that's not what they would provide, I guess. (Interviewee 8)

Not only do the library staff feel that they cannot tackle the topic of misinformation, but also they feel that their partners would not be able to address it. They felt that it is even more difficult in the context of specific topics, since they do not have the time to keep up with all the possible misinformation that might arise with new forms of programming. One workshop participant discussed this in relation to a new program on transgendered identities:

So, then having just gone through a controversial transgenderrelated situation, I think one of the things that we could have done better ... way better ... is we should have educated ourselves as an institution about what strands of misinformation are out there. Because some of the things that were being said, and a potential thread about this, were so outlandish that we would not have come up with that. If we were planning it ourselves . . . who would say that. But then it happened. And then we were kind of like, that's what they were saying? So, that's one thing. (Workshop Participant) 
In most cases, though, librarians already lack the time and resources to plan the programs themselves - training themselves to identify emerging misinformation across all their programs is just too much of an addition to their job responsibilities. Many workshop participants, therefore, felt that researchers could be vital partners by providing them with tools and training to expand their capacity to address misinformation across their programming. As one interviewee explained,

Our most scarce resource is time and so if we could have things ready for library staff to bring to partners or bring to each other, to talk about this topic, I think that would be really helpful. [. . . If there is data that would show that there are certain products or resources that are helpful to have in a learning environment for people to understand misinformation, potentially, I would see a greater need in some of those other areas. (Interviewee 4)

At the workshop, one of the researchers asked if it would be useful to have a portal that librarians could use to look up "fact cards" on widespread misinformation across a range of topics. There was widespread enthusiasm for this idea, and participants contributed other ideas that they would like to see in such a platform - such as graphs of the prevalence of different misinformation narratives over time. Another interviewee felt that it was important to build more partnerships with misinformation scholars themselves, so that, they could come in and give expert discussions about misinformation across the different library programs. Ultimately, more research is needed to understand the best tools, training, and other forms of engagement that might be used to equip librarians to engage this difficult terrain.

\section{Libraries and the broader political economy}

Finally, it is important to fully understand how the broader political and economic contexts of libraries constrain the types of misinformation interventions that libraries can make. Research is needed to help librarians (and administrators) understand how they can frame their programming so that it makes a difference without endangering their funding and community partnerships. Most public libraries are highly dependent on funding from local sources, meaning that they need to strongly consider how their actions might impact local support. In 2017, for example, the proportion of funding that Washington libraries receive from local government averaged 95\% in Washington (Pelczar et al., 2019). Funding for public libraries still has not fully recovered from the 2008-2009 recession, and public support for library levies has continued to decline since that time period (OCLC, 2018). Given this context, misinformation can be a very difficult topic for librarians. Many of our participants emphasized that it is difficult to engage with highly contentious topics because it can anger the patrons and community partners on whom they rely. Our participants from rural libraries, in particular, worried that their communities were highly conservative, and misinformation is often thought of as a liberal topic. As one interviewee put it, "I don't believe that it [the correct framing] is, 'come and learn about disinformation.' I think that that will always sort of appear to have a liberal bias, if that makes sense" (Interviewee 3). More generally, workshop participants felt that misinformation cultivated an us-versus-them mentality that could easily lead the public to viewing librarians as an enemy. They felt that misinformation programming would bring patrons to the library with feelings of pre-emptive rage, which would undermine their programming for everyone. In the end, many felt the need to continue framing the library as a neutral political space, even when trying to make positive contributions in the area of misinformation:

I mean, the problem is that when it becomes political, yeah, like the [anti-]vax thing . . . I wouldn't . . . we wouldn't touch that, because it's too political. And where [library name omitted] is at right now is that we are in a place where we're very tied to neutrality. (Interviewee 5)

Of course, many librarians are currently grappling with the idea of neutrality and how libraries should orient themselves toward political values (e.g. Neal et al. 2020; Peet and Schwartz, 2020). This participant, for example, goes on to say that they personally think that the library should take a stand on issues like vaccination, since fueling misinformation in this area can have real negative health consequences. However, he finds that "we still are in a place where public libraries have been stuck sometimes where we are too worried about being neutral and not worried enough about how much harm is being done" (Interviewee 5 ). He is describing a very difficult risk calculus that libraries need to make whenever they choose to engage a controversial or political topic. Similarly, at the workshop many participants discussed their emphatic support for recent transgender programming. At the same time, there was recognition, particularly among library managers, that this programming had to be approached very carefully. Given its controversial political nature, misinformation programming is intrinsically caught within this ongoing debate about neutrality within the LIS field.

One possible solution to these problems is to rely on partnerships across the community, so that they can use these partners to share the risk. However, this once again requires a lot of political work by libraries, to ensure that they are building strong partnerships that will help them weather any political fallout. As a workshop participant argued,

There may be sections of the larger community in which we could always address something. But, the timing and the communication and the partnerships and the education piece 
to get our partners on board with this, so that we're not the sole entity offering a program that is controversial. That we've got people in really strategic places within the community that are going to be able to talk with and spread the word why the library exists and why we're offering this program [...] Without that, then we are a lone duck in a community that could turn really hostile. (Workshop Participant)

This participant argued that regional managers should be taking on the role of politicians to help their libraries navigate these political issues. In this sense, she believed that regional managers should have their ears constantly to the ground within their communities, with a constant understanding of needs and controversies. This is important not only because it can help avoid controversy that will negatively affect program participation, but also to avoid public outcry that could lead to funding cuts.

And, in fact, even current resource levels are inadequate to allow libraries to develop effective misinformation programming. Participants identified a wide range of resources that they are lacking: funding, expertise, time and capacity, technology, and more. This directly impacts their ability to take on misinformation. Returning to Sullivan (2018), one criticism of libraries is that they have not performed sufficient evaluation of the misinformation programming that they have carried out. Our participants pointed out that this is not for a lack of interest in evaluation - they want to be implementing effective programming, and they would love to improve their programs based on feedback or evaluation data. The reality, however, is that they just do not have the capacity to perform the sort of rigorous social science evaluation described by scholars like Sullivan. They lack both the expertise to perform rigorous, longitudinal evaluation of the impact of programming on patron behavior, and also the resources to carry out this evaluation. As a result, they are forced to rely on less rigorous forms of evaluation, such as anecdotal feedback from patrons or attendance counts. Even given recent pushes for measuring outcomes (e.g. project outcome), there is still largely a lack of funding and support for these evaluation activities. This is another area where researchers could potentially help to expand the capacity of librarians. LIS scholars, for example, could develop and test curriculum and teaching tools that are proven to combat misinformation, and provide them openly for local customization by librarians. This might diminish the need for librarians themselves to rigorously evaluate new curriculum. Education scholars can also develop more advanced tools to support librarians in evaluating their own programming - or even partner with them to perform the evaluation - so that, the librarians themselves need less expertise and staff time to carry out evaluation.

Finally, many communities themselves do not have adequate resources to take advantage of library programming on misinformation, even if they are interested. As was previously mentioned, people within many communities are resource and time constrained, so they do not have an incentive to go to library programming that is not immediately valuable to them. Librarians also brought up issues of digital equity, arguing that some patrons do not have adequate technology access or technical literacy to fully take advantage of programming about misinformation. Some patrons may not receive misinformation directly from social media platforms, but they could be exposed to it as it filters through other members of their community. One interviewee, for example, discussed the difficulty of engaging people about misinformation within a community in which two generations are technologically illiterate. As they argue,

This is one of my big concerns as an aside about technology and access and information is. You know, we are now seeing the second generation of technologically illiterate people. [. . . ] so we're raising another generation which has its own level of really complicated issues that go along with this and so that's, you know . . . access to information . . . we've tried all kinds of creative things through those multiple partners like Wi Fi checkouts where people could take them home. But many places don't have cell phone access, like where I live, in my house there's no cell phone coverage. There's no internet coverage. My phone lines are so bad. I don't even have a voicemail as an option. So, you know, you're talking about just basic infrastructure stuff that's pretty systemic. (Interviewee 9)

These complex issues raise questions that extend beyond misinformation studies itself, but that must be answered to actually address misinformation. How should libraries position themselves politically within their communities, particularly in light of ongoing discussions of neutrality? What broader social or political issues should libraries more proactively engage (e.g. Lankes, 2020)? How can libraries engage with an increasingly divided public while sustaining necessary public support? How can they contribute to digital equity so that it is easier to reach patrons that most need training related to misinformation? Naturally, answer to these questions will vary by geography and community, and this initial, exploratory study has only grazed the surface of these complex issues. Fuller sets of answers require more expansive partnerships between librarians and interdisciplinary teams of scholars ready to explore broad and complex political and economic research topics.

\section{Conclusion}

When a new phenomenon emerges within a field, initial responses can tend toward simplicity-researchers and practitioners alike often respond with either some degree of naive optimism or fear. This has occurred to some extent within LIS, as we initially responded to the emergence of misinformation with great optimism for the role that libraries might play. Researchers like Sullivan (2018, 2019) have helped to deflate this initial optimism a little, and they point toward the hard work that the field needs to 
tackle to really make a difference as communities grapple with misinformation. We argue that even this initial criticism, though, has not fully appreciated the complex challenges that librarians need to navigate to develop misinformation programming.

This article offers an empirical study of how librarians have experienced and reacted to misinformation in their communities. The research shows that librarians do understand many of the difficulties of designing programming for misinformation, and that they are excited to tackle these challenges. However, a great deal of work still needs to be done. By design, this was an exploratory pilot project, which targeted a subset of libraries within a single state. We worked hard to ensure that the research represented a wide range of perspectives, from librarians in small, rural districts to those serving large urban populations. Participants also ranged from frontline librarians to library system administration. Nevertheless, an important next step will be to scale up the research, to more broadly understand how librarians across the United States and beyond are encountering and responding to misinformation in their communities. Library organizations, such as the ALA, could have an important role to play in conducting more systematic and widespread surveys of the field, to make the largest possible impact.

More applied work needs to be done as well, to provide librarians with effective approaches to combatting misinformation. Already, this article hints at some concrete steps that librarians can be taking. In some cases, libraries should recognize that they are already carrying out programming that has an indirect impact on misinformation, and they should continue to engage in these activities. Libraries have historically played a critical role as trusted community anchors, always listening to understand the needs of their community and respond with relevant programming. Misinformation is most dangerous when it is able to exploit the fears and needs of communities. If librarians are able to bring their community together to solve problems before they become the target of a disinformation campaign, then this is a valuable contribution even if the library never directly address the topic of misinformation itself. Similarly, many other forms of programming — such as technology literacy training - can have an impact on the complex information ecosystem that supports misinformation. Libraries should continue working toward these strengths. At the same time, there is plenty of room to think more creatively about how to address misinformation more directly. Traditional media and information literacy approaches do not account for the new media ecosystem in which misinformation thrives, and do not account for the complex psychological impacts of misinformation. Programming cannot treat this as simply a problem of truth - it needs to recognize that misinformation exploits community values, political partisanship, emotion, social well-being, and much more. Misinformation is most effective, and most dangerous, when it creates emotionally and socially affirming communities based on falsehood. Programming cannot simply take these communities away and replace it with cold truths - it must also help patrons forge new communities based on that truth. Finally, librarians need to recognize not only that their patrons are impacted by misinformation, but also that disinformation campaigns have the potential to disrupt any of the activities going on at libraries. Our participants described how their programming is increasingly disrupted by patrons using misinformation or conspiracy theories. Particularly as librarians design new programming, they need to have a digital ear to the ground so that they can understand what relevant misinformation is circulating. This can help them more effectively respond to that misinformation when it is weaponized against a program.

Of course, much of this is easier said than done. Librarians face many barriers to doing these things, and an even more difficult time designing, implementing, and evaluating programming that is actually effective against misinformation. Librarians need new partnerships to overcome these barriers, and LIS researchers have the potential to play a critical role within these partnerships. This article has identified three areas in which academic partners might help libraries to more effectively combat misinformation - through the design of effective programming, through the development of tools that help librarians keep up-to-date on relevant misinformation, and through interventions in the political and economic contexts that hamper the freedom of librarians to engage controversial topics. Our hope is that this article can help to spur more expansive LIS research across these areas and become the beginning of a longer and more empirically grounded conversation about how libraries can achieve their potential for combating misinformation.

\section{Declaration of conflicting interests}

The author(s) declared no potential conflicts of interest with respect to the research, authorship, and/or publication of this article.

\section{Funding}

The author(s) received no financial support for the research, authorship, and/or publication of this article.

\section{ORCID iDs}

Jason C. Young (iD https://orcid.org/0000-0003-2537-4255

Stacey Wedlake iD https://orcid.org/0000-0002-7471-321X

\section{References}

ALA (2005) Resolution on disinformation, media manipulation \& the destruction of public information. Progressive Librarians' Guild. Available at: http://www.progressivelibrariansguild. org/PL/PL26/068.pdf (accessed 14 September 2020).

ALA (2018) Resolution on disinformation, media manipulation and the destruction of public information. American Library Association. Available at: http://www.ala.org/news/member-news/2017/02/new-resolution-addresses-accurate-information-and-media-manipulation (accessed 10 June 2020). 
ALA (2019) Evaluating Information: Information Literacy. American Library Association. Available at: https://libguides.ala.org/InformationEvaluation/Infolit (accessed 14 September 2020).

Allcott H, Gentzko M and Yu C (2019) Trends in the diffusion of misinformation on social media. Research and Politics 2019: 1-8.

Asr FT and Taboada M (2018) The data challenge in misinformation detection. In: Proceedings of the first workshop on fact extraction and verification (FEVER), Brussels, Belgium, 1 November 2018, pp. 10-15. Association for Computational Linguistics.

Banks M (2016) Fighting fake news: How libraries can lead the way on media literacy. American Libraries, December. Available at: https://americanlibrariesmagazine. org/2016/12/27/fighting-fake-news/

Baxter J and Eyles J (1997) Evaluating qualitative research in social geography. Transactions of the Institute of British Geographers 22(4): 505-525.

Becker BW (2016) The librarian's information war. Behavioral \& Social Sciences Librarian 35(4): 188-191.

Bluemle S (2018) Post-facts: Information literacy and authority after the 2016 election. Libraries and the Academy 18(2): 262-282.

Braten I, Brante EW and Stromso HI (2019) Teaching sourcing in upper secondary school: A comprehensive sourcing intervention with follow-up data. Reading Research Quarterly 54(4): 481-505.

Caulfield M(2016) Yes, digital literacy. But which one? Hapgood. Available at: https://hapgood.us/2016/12/19/yes-digital-literacy-but-which-one/ (accessed 14 September 2020).

Choy M and Chong M (2018) Seeing through misinformation: A framework for identifying fake online news. arXiv preprint. Available at: https://arxiv.org/abs/1804.03508

Clarke AE (2003) Situational analyses: Grounded theory mapping after the postmodern turn. Symbolic Interaction 26(4): 553-576.

Cook J, Ellerton P and Kinkead D (2018) Deconstructing climate misinformation to identify reasoning errors. Environmental Research Letters 13: 11-17.

Cooke NA (2017) Posttruth, truthiness, and alternative facts: Information behavior and critical information consumption for a new age. The Library Quarterly 87(3): 211-221.

Cooke NA (2018a) Critical literacy as an approach to combating cultural misinformation/disinformation on the Internet. In: Agosto's D (ed.) Information Literacy and Libraries in the Age of Fake News. Santa Barbara, CA: ABC CLIO, pp. 36-51.

Cooke NA (2018b) Fake News and Alternative Facts: Information Literacy in a Post-truth Era. Chicago, IL: American Library Association.

Crocco M, Halvorsen AL, Jacobsen R, et al. (2017) Teaching with evidence. Phi Delta Kappan 98(7): 67-71.

Dempsey K (2017) What's behind fake news and what you can do about it. Information Today Inc. Available at: http:// www.infotoday.com/it/may17/Dempsey-Whats-BehindFake-News-and-What-You-Can-Do-About-It.shtml

Ecker UKH and Ang LC (2018) Political attitudes and the processing of misinformation corrections. Political Psychology 40(2): 241-260.
Farrell J, McConnell K and Brulle R (2019) Evidence-based strategies to combat scientific misinformation. Nature Climate Change 9: 191-195.

Fernandez M and Alani H (2018) Online misinformation. In: World Wide Web conference, Lyon, 23-27 April.

Glaser BG (1978) Advances in the Methodology of Grounded Theory: Theoretical Sensitivity. New York: The Sociology Press.

Henderson J, Long D, Berger P, et al. (2017) Expanding the foundation: Climate change and opportunities for educational research. Educational Studies 53(4): 412-425.

Hodgin E and Kahne J (2018) Misinformation in the information age. Social Education 82(4): 208-211.

Ireland S (2017) For your information: Using information literacy in public libraries. Reference \& User Services Quarterly 57(1). Available at: https://journals.ala.org/index.php/rusq/ article/view/6436/8503

Jacobson L (2017) The smell test: Educators can counter fake news with information literacy. Here's how. School Library Journal, January. Available at: https://www.slj. $\mathrm{com} /$ ?detailStory=the-smell-test-educators-can-counterfake-news-with-information-literacy-heres-how (accessed 14 September 2020).

Kenney B (2017) Three critical issues facing librarians in Trump's America. Publishers' Weekly, January. Available at: https://www.publishersweekly.com/pw/by-topic/industry-news/libraries/article/72493-libraries-in-the-age-oftrump.html (accessed 14 September 2020).

Kim J, Tabibian B and Oh A (2018) Leveraging the crowd to detect and reduce the spread of fake news and misinformation. WSDM 2018: 324-332.

Kitchin R and Tate NJ (2000) Conducting Research in Human Geography. Upper Saddle River, NJ: Prentice Hall.

Koester A (2019) A civic initiative about information: The civic lab at Skokie Public Library. Public Libraries 58(4): 44-52.

Koulolias V, Jonathan GM, Fernandez M, et al. (2018) Combating Misinformation: An Ecosystem in Co-Creation. Paris: OECD.

Lankes D (2020) The "new normal" agenda for librarianship. Available at: https://davidlankes.org/the-new-normal-agendafor-librarianship/ (accessed 26 May 2020).

LaPierre SS and Kitzie V (2019) Lots of questions about 'fake news': How public libraries have addressed media literacy, 2016-2018. Public Library Quarterly 38(4): 428-452.

Lewandowsky S, Ecker UKH and Cook J (2017) Beyond misinformation. Journal of Applied Research in Memory and Cognition 6: 353-369.

Li H and Sakamoto Y (2014) Social impacts in social media. Computers in Human Behavior 41: 278-287.

Marks J (2020) The cybersecurity 202: Disinformation threat pushes Doomsday Clock closer to midnight. The Washington Post. Available at: https:/www.washingtonpost.com/news/ powerpost/paloma/the-cybersecurity-202/2020/01/24/thecybersecurity-202-disinformation-threat-pushes-doomsday-clock-closer-to-midnight/5e29d32d88e0fa6ea99d3426/ (accessed 10 June 2020).

Merkeley E (2020) Anti-intellectualism, populism, and motivated resistance to expert consensus. Public Opinion Quarterly 84(1): 24-48. 
Neal J, LaRue J, Bourg C, et al. (2020) Are libraries neutral? American Libraries Magazine. Available at: https://americanlibrariesmagazine.org/2018/06/01/are-libraries-neutral/ (accessed 10 June 2020).

Neely-Sardon A and Tignor M (2018) Focus on the facts: A news and information literacy instructional program. The Reference Librarian 59(3): 108-121.

OCLC (2018) From Awareness to Funding: Voter Perceptions and Support of Public Libraries in 2018. Dublin, OH: OCLC.

Peet L and Schwartz M (2020) The Seattle Public Library Listens Up. Library Journal. Available at: https://www. libraryjournal.com/?detailStory=Seattle-Public-LibraryListens-Up-Gale-LJ-Library-of-the-Year-2020 (accessed 10 June 2020).

Pelczar M, Frehill LM, Williams K, et al. (2019) Public Libraries Survey: Fiscal Year 2017. Washington, DC: Institute of Museum and Library Services.

Pelczar M, Frehill LM, Nielsen E, et al. (2020) Data File Documentation: Public Libraries in the United States Fiscal Year 2018. Washington, DC: Institute of Museum and Library Services. Available at: https://www.imls.gov/ sites/default/files/pls_fy2018_data_files_csv.zip (accessed 14 September 2020).

Pulido CM, Villarejo-Carballido B, Redondo-Sama G, et al. (2020) COVID-19 infodemic: More retweets for sciencebased information on coronavirus than for false information. International Sociology 35: 377-392.

Scheufele DA and Krause NM (2019) Science audiences, misinformation, and fake news. PNAS 116(16): 7662-7669.

Simpson M, Srinivasan V and Thorno A (2019) Scalable misinformation prevention in social networks. PVLDB 12: 1-14.

Sullivan MC (2018) Why librarians can't fight fake news. Journal of Librarianship and Information Science 51(4): 1146-1156.

Sullivan MC (2019a) Libraries and fake news: What's the problem? What's the plan? Communications in Information Literacy 13(1): 91-113.

Sullivan MC (2019b) Leveraging library trust to combat misinformation on social media. Library \& Information Science Research 41: 2-10.

Van der Linden S, Leiserowitz A, Rosenthal S, et al. (2017) Inoculating the public against misinformation about climate change. Global Challenges 1: 1600008.

Wade S and Hornick J (2018) Stop! Don't share that story! Designing a pop-up undergraduate workshop on fake news. The Reference Librarian 59(4): 188-194.

World Health Organization (WHO) (2020) Novel coronavirus (2019nCoV): Situation report 13. Available at: https://www.who.int/ docs/default-source/coronaviruse/situation-reports/20200202sitrep-13-ncov-v3.pdf (accessed 10 June 2020).

Zaracostas J (2020) How to fight an infodemic. The Lancet. Available at: https://www.thelancet.com/journals/lancet/article/PIIS01406736(20)30461-X/fulltext (accessed 21 May 2020).

\section{Author biographies}

Jason C. Young is a researcher with the University of Washington (UW) Information School, where he explores the role of digital technologies in supporting new forms of politics, knowledge production, and community resilience. He received his $\mathrm{PhD}$ from the UW Department of Geography in 2017.

Brandyn Boyd is currently a Master of Library and Information Science (MLIS) student at the UW Information School. She is also a founder of the Magnolia Forest Preschool, where she is passionate about empowering youth through knowledge creation and exploration of nature.

Katya Yefimova is a $\mathrm{PhD}$ Candidate at the iSchool studying the role of public libraries in the civic life of immigrant and refugee communities. Katya works with libraries and organizations to codesign inclusive programs and services for immigrants and refugees. She has a background in journalism.

Stacey Wedlake is a research coordinator and analyst with the Technology \& Social Change Group at the UW Information School. She holds degrees in Public Administration (MPA) and Library and Information Science (MLIS) from the University of Washington.

Chris Coward is a senior principal research scientist at the UW Information School, where he is also director of the Technology \& Social Change Group and co-founder of the Center for an Informed Public. He studies issues of information access, digital equity, misinformation, and civic engagement, with much of his research involving public libraries.

Rolf Hapel is an affiliate instructor at UW Information School. He served in the "Distinguished Practitioner in Residence" program as professor of Practice from 2018 to 2020 . He was director of Citizens' Services and Libraries in Aarhus, Denmark, from 2006 to 2018, responsible for planning and completion of the acclaimed library Dokk1 in 2015, and city librarian from 1994 to 2006. He is a librarian by education and holds a master's degree in Digitization and Public Administration. He has served as librarian, deputy manager, city librarian, and director in four Danish cities, has served as expert in architectural competitions for new city libraries in the capitals of Norway and Finland and has worked with different international foundations as advisor in the library field. 